\title{
Venous Pressure in Congestive Heart Failure in Infancy
}

\author{
R. H. BURNELL \\ From the Department of Paediatrics, Brompton Hospital, London
}

\begin{abstract}
Burnell, R. H. (1970). Archives of Disease in Childhood, 45, 360. Venous pressure in congestive heart failure in infancy. A retrospective study was made of the mean right atrial pressure in 131 infants with congenital heart disease. 56 are considered to have been in congestive heart failure at the time of cardiac catheterization, and 75 patients are considered not to have been so. The mean value for mean right atrial pressure was $7.7 \mathrm{~mm}$. in the group who were in heart failure compared with $3.5 \mathrm{~mm}$. in the group not in heart failure.
\end{abstract}

In 1962 Moss and Duffie reported that infants, unlike adults, do not have a raised venous pressure when in congestive heart failure, hence suggesting 'the possibility that the hemodynamic alterations of the failing heart in children may not be the same as those in adults'. They observed also that the clinical manifestations were different in the two groups-'venous distension and demonstrable peripheral oedema, common findings in adults, are not usually observed in infants-even in the most advanced cases'.

Since venous distension, seen particularly in the scalp veins of such babies, is fairly common, and peripheral oedema is not strikingly rare, the problem of the venous pressure was re-evaluated by a procedure similar to that of Moss and Duffie (1962).

\section{Material and Methods}

Three criteria were used for retrospective diagnosis of congestive cardiac failure, and these all had to be present: (1) a liver palpable $3 \mathrm{~cm}$. or more below the costal margin, (2) persistent sleeping respiratory rate of 60 per minute or more, obtained from the hourly nursing observations of the night before cardiac catheterization, and (3) radiological cardiomegaly. If observations (1) and (3) were made more than 24 hours before catheterization, the cases were retained in the heart failure group only if item (2) was still present, and there had been no significant weight loss in response to treatment. The presence of peripheral oedema and diffuse pulmonary râles was noted only to confirm the impression of heart failure.

Adequate clinical data were available for 131 patients under 1 year of age. Using the above criteria, 56 are

Received 22 October 1969. considered to have been in congestive cardiac failure at the time of cardiac catheterization and are referred to as the heart failure group. The remaining 75 cases are considered not to have been in cardiac failure and are referred to as the control group. The diagnoses listed in the Table for both groups are those obtained from the haemodynamic data, supplemented in almost every case by selective angiography and confirmed in approximately $65 \%$ by operation or necropsy. The groups are not balanced with regard to diagnoses, the presence of congestive heart failure being the only criterion for separation. The patients were all classified before their original haemodynamic recordings were inspected, in an attempt to eliminate bias.

Cardiac catheterization had been performed in the one laboratory with identical equipment. Right atrial pressures were measured at the mid-right atrial border through No. 5 or 6 Goodale-Lubin catheters by a conventional manometry system, the zero reference point being mid-thorax. The system was calibrated before and after each procedure against a mercury manometer. The recorded deflection of $5 \mathrm{~mm}$. was equal to $1 \mathrm{~mm}$. $\mathrm{Hg}$. Mean right atrial pressures were obtained by electrical integration. The right atrial pressures used in this study were those recorded at the beginning of each procedure, i.e. before removal of blood samples or angiography.

The infants were all studied in the fasting state. No allowance is made for sedation or anaesthesia; in both groups some infants had only a pacifier or basal sedation, while some had general anaesthesia with endotracheal intubation.

\section{Results}

These are shown graphically (Fig.). The control group had mean right atrial pressures ranging from 0-8 mm. Hg (mean $=3.5, \mathrm{SD} \pm 1.6 \mathrm{~mm}$. Hg), 


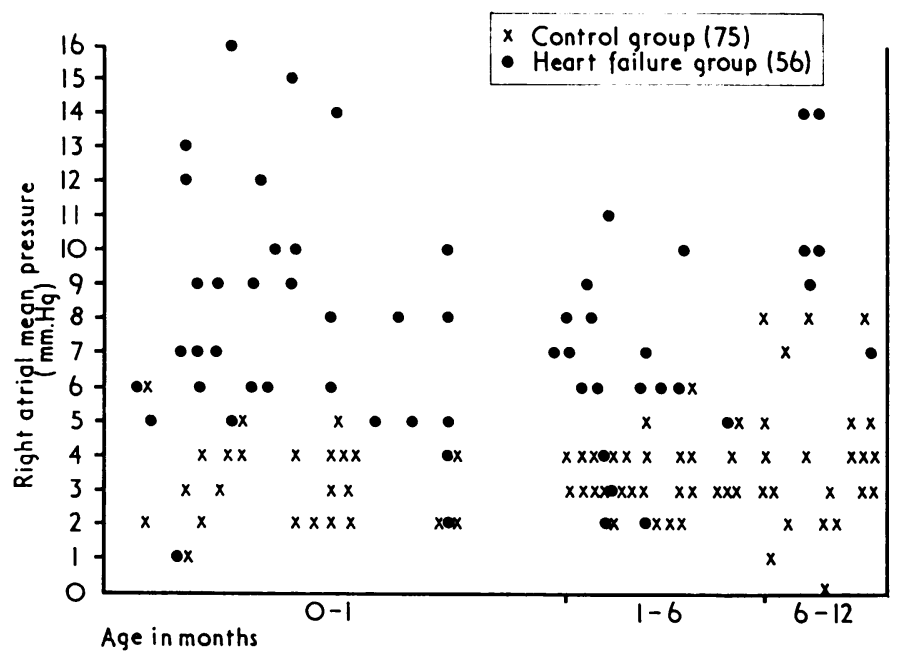

FIG.-Right atrial mean pressures in congestive heart failure group (56 cases), and control group (75 cases).

only 6 cases being above $5 \mathrm{~mm}$. $\mathrm{Hg}$. Of these exceptions, 5 had critical or complete pulmonary valve obstruction, including 3 cases of pulmonary valve stenosis with intact ventricular septum, and 2 cases of large ventricular septal defect with pulmonary valve atresia. The sixth was a case of isolated ventricular septal defect who was admitted in gross heart failure several weeks before study, but had a large diuresis (approximately $8 \%$ of total body weight) on treatment.

The group in heart failure had mean right atrial pressures ranging from $1-17 \mathrm{~mm} . \mathrm{Hg}$ (mean $=7 \cdot 7$, $\mathrm{SD} \pm 3.4 \mathrm{~mm}$. $\mathrm{Hg}$ ). Only 7 cases had a mean right atrial pressure below $5 \mathrm{~mm}$. $\mathrm{Hg}$. Of these, 2 cases had concurrent septicaemia with Gramnegative organisms, 1 case had collapsed several hours before the procedure and was studied when the systemic pressure was $40 \mathrm{~mm}$. $\mathrm{Hg}$, and the infant required intermittent positive pressure ventilation; and 1 case presented the combination of severe aortic stenosis in congestive heart failure while being clinically dehydrated from intercurrent gastro-enteritis.

Student's $t$ test showed the difference in the mean right atrial pressures between the two groups to be significant $(\mathrm{p}<0.001)$.

\section{Discussion}

$5 \mathrm{~mm} . \mathrm{Hg}$ is usually accepted as the upper limit of mean right atrial pressure in normal infants and children. The usual reference is that of Rudolph et al. (1961), which is not strictly comparable, as the subjects in that study were all less than 36 hours old. Nevertheless it is in accordance with the values found in the present control group. Thus the results presented for the congestive heart failure group show that the vast majority of such infants as defined here do have high mean right atrial pressure. This is in agreement with Osano et al. (1967) who recorded raised venous pressure in infants in heart failure by sagittal sinus puncture. In that study as in the present one, the definition of heart failure was on clinical signs at the time of venous pressure measurement. Unlike us, Osano et al. repeated their measurements as the infants improved clinically, and they showed a coincident fall in venous pressure. Similarly Keith, Rowe, and Vlad (1967), quoting some apparently unpublished work of Kidd and Collins, concluded that right atrial pressure in 'those with failure averaged $9 \mathrm{~mm}$. of mercury and those without, $3 \mathrm{~mm}$. of mercury'-figures rather similar to those of the present investigation.

There are probably several reasons for the differences from the findings of Moss and Duffie (1962). Certainly their criteria of diagnosis, i.e. a recorded diagnosis of 'congestive failure', a record of appropriate therapy, and clinical notes indicating a lack of response to the therapy, are different. The case selection was different in that Moss and Duffie accepted as infants children up to 2 years of age. In addition their Table I lists the clinical signs of 22 cases of congestive heart failure. Of these, one did not have tachypnoea and 3 did not have hepatomegaly; they would not therefore have been 
TABLE

Diagnoses in Infants Studied

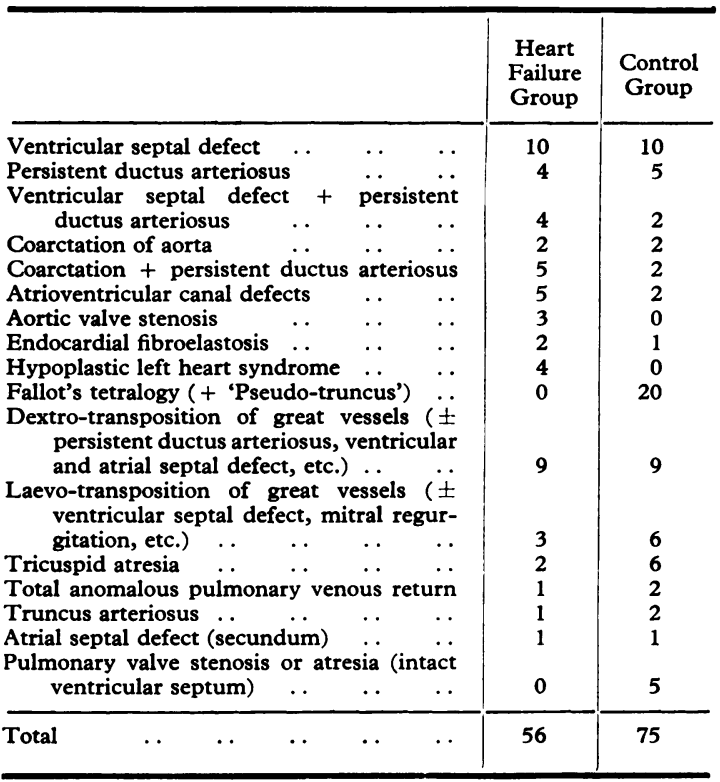

included in the congestive heart failure group in this series.

The mechanisms of congestive heart failure in infants have not been studied as much as in adults, but certain similarities such as diminished glomerular filtration rate, increased blood volume and raised urinary excretion of aldosterone have been shown (Talner et al., 1966). An increase of venous pressure in adult congestive heart failure has been linked with increased adrenergic activity and venoconstriction (Wood, 1962; Mason and Braunwald, 1968). While this has not apparently been separately proven in infants, increased $\frac{\rho}{\bar{\partial}}$. catecholamine biosynthesis in congestive heart failure has been shown in infants (Lees, 1966) as in $\underset{\overrightarrow{\mid}}{\vec{\rho}}$ adults (Chidsey, Braunwald, and Morrow, 1965). Therefore, in view of the demonstration of increased venous pressure in infants given here, it is difficult $\frac{\omega}{\omega}$ to support the postulate that the haemodynamic alterations of the failing heart in infancy are necessarily different from those in adults.

My thanks are due to Dr. M. C. Joseph under whose care all the patients were admitted, and Dr. G. A. H. Miller who performed or supervised the cardiac catheterizations. This work was carried out during the tenure of a research fellowship, supported by the Board of Governors, Brompton Hospital, London S.W.3.

\section{REFERENCES}

Chidsey, C. A., Braunwald, E., and Morrow, A. G. (1965). Catecholamine excretion and cardiac stores of norepinephrine in congestive heart failure. American fournal of Medicine, 39, 442.

Keith, J. D., Rowe, R. D., and Vlad, P. (1967). Heart Disease in Infancy and Childhood, 2nd ed., p. 1025. Macmillan, New York.

Lees, M. H. (1966). Catecholamine metabolite excretion of infants with heart failure. Fournal of Pediatrics, 69, 259.

Mason, D. T., and Braunwald, E. (1968). Digitalis: new facts about an old drug. American fournal of Cardiology, 22, 151.

Moss, A. J., and Duffie, E. R., Jr. (1962). Congestive heart failure in infancy: significance of the venous pressure. Fournal of Pediatrics, 60, 346.

Osano, M., Fujimoto, E., Yashiro, K., Oikawa, T., and Tsuji, A. (1967). Venous pressure measurements in infants with and without heart failure. Acta Paediatrica faponica, 8, 7.

Rudolph, A. M., Drorbaugh, J. E., Auld, P. A. M., Rudolph, A. J., Nadas, A. S., Smith, C. A., and Hubbell, J. P. (1961). Studies on the circulation in the neonatal period: the circulation in the respiratory distress syndrome. Pediatrics, 27, 551.

Talner, N. S., Sanyal, S. K., Gardner, T. H., Rivard, G., and Halloran, K. H. (1966). The biochemical alterations associated with congestive heart failure in infancy. In The Heart and Circulation in the Newborn and Infant, p. 162. Ed. by D. E. Cassels. Grune and Stratton, New York.

Wood, J. E. (1962). The mechanism of the increased venous pressure with exercise in congestive heart failure. Fournal of Clinical Investigation, 41, 2020.

Correspondence to Dr. M. C. Joseph, Paediatric Department, Brompton Hospital, London S.W.3. 